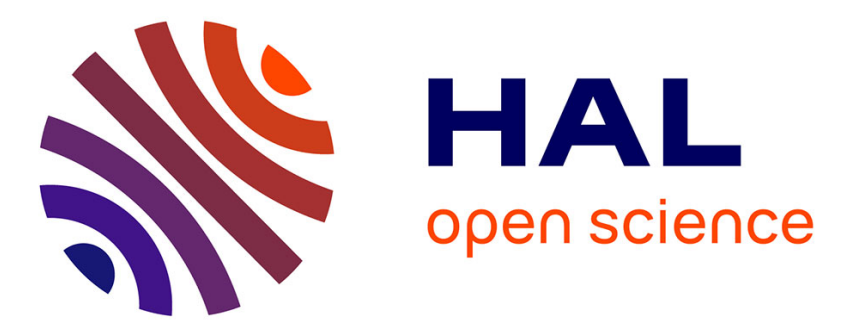

\title{
Project and Engineering Management in the Era of Industry 4.0 - An Overview of Learning Requirements
}

Khaled Medini, Julien de Benedittis, Stefan Wiesner

\section{To cite this version:}

Khaled Medini, Julien de Benedittis, Stefan Wiesner. Project and Engineering Management in the Era of Industry 4.0 - An Overview of Learning Requirements. ARV 2021, MCPC 2021: Towards Sustainable Customization: Bridging Smart Products and Manufacturing Systems, Nov 2021, Aalborg, Denmark. pp.919-926, 10.1007/978-3-030-90700-6_105 . emse-03432847

\section{HAL Id: emse-03432847 https://hal-emse.ccsd.cnrs.fr/emse-03432847}

Submitted on 18 Nov 2021

HAL is a multi-disciplinary open access archive for the deposit and dissemination of scientific research documents, whether they are published or not. The documents may come from teaching and research institutions in France or abroad, or from public or private research centers.
L'archive ouverte pluridisciplinaire HAL, est destinée au dépôt et à la diffusion de documents scientifiques de niveau recherche, publiés ou non, émanant des établissements d'enseignement et de recherche français ou étrangers, des laboratoires publics ou privés. 


\title{
Project and engineering management in the era of Industry 4.0 - an overview of learning requirements
}

\author{
Khaled Medini ${ }^{1}$, Julien De Benedittis ${ }^{2}$, Stefan Wiesner ${ }^{3}$ \\ ${ }^{1}$ Mines Saint-Etienne, Univ Clermont Auvergne, CNRS, UMR 6158 LIMOS, Henri Fayol Institute, F - \\ 42023 Saint-Etienne France khaled. medinidemse. fr \\ ${ }^{2}$ Mines Saint-Étienne, Univ. Jean Monnet Lyon, EA 4161 CoActis, Institut Henri Fayol, 158 cours \\ Fauriel, 42023 Saint-Étienne, France \\ ${ }^{3}$ BIBA-Bremer Institut für Produktion und Logistik GmbH, at the University of Bremen, Hochschulring \\ 20, 28359 Bremen, Germany
}

\begin{abstract}
Organizations have been witnessing several transformations due to the integration of new technologies and concepts in the Industry 4.0 era. With these transformations come several challenges such as financial investments for organizations desiring to adopt Industry 4.0 related methods and tools and most importantly finding engineering and project managers who are well equipped with the right competencies to be able to pilot industry transformation projects. The current paper studies learning requirements in the field of project and engineering management within Industry 4.0 Era. A combined literature analysis and interview method is adopted in order to overcome the lack of state of the art. The results underline the key role of project and engineering manager as integrators.
\end{abstract}

Keywords: Engineering management, project management, learning, engineering education, industry 4.0.

\section{Introduction}

In recent years we have witness a new transformation in organizations due to the integration of new technologies in what is known as the Industry 4.0 Era. With this transformation comes a lot of challenges, mainly financial investments for organizations desiring to adopt Industry 4.0 related methods and tools. However, the major challenge firms are faced with relates to their ability to find project and engineering managers who are well equipped with the right competencies to manage the transformation of the organization. Yet these competencies are to be identified and categorized in order to adapt training programmes in the broad field of project and engineering management. While several initiatives have arisen throughout the recent years, there are still efforts to be conducted for two main reasons. First, most of the initiatives dealing with Industry 4.0 competencies are focusing on specific disciplines. Second, no previous research has specifically addressed the state of the art in this topic.

The current paper studies learning requirements in the field of project and engineering management within Industry 4.0 Era. A combined literature analysis and interview method is adopted in order to overcome the lack of state of the art. The interviews underline the key role of project and engineering manager as integrators. More generally, the results are expected to 
contribute to develop academic and continuous professional training to prepare the next generation of engineers to better handle the Industry 4.0 transformation. The remainder of the paper is organised as follows, section 2 provides an overview of the key concepts namely project management, engineering management and Industry 4.0. Section 3 draws insights into required skills to deal with the intersecting areas of project and engineering management and Industry 4.0. Section 4 reports on the results from the interviews conducted among experts. The paper ends with concluding remarks in Section 5.

\section{Concepts overview}

\subsection{Industry 4.0}

Industry 4.0 can be defined as a collective term for digitalization technologies and concepts of value chain organization, which enable modular structured Smart Factories based on Cyber Physical Systems (CPS). They monitor physical processes, interact with the physical world and make decentralized decisions. Embedded in the Internet of Things (IoT), CPS communicate and cooperate with each other and humans in real time, creating a Digital Twin of assets and processes. This facilitates fundamental improvements and flexibility to the industrial processes of the value chain. In addition products become smart and identifiable with a known history and a real time tracking due to identification technologies such as RFID tags and Big Data analysis (Calisir and Akdag, 2017).

However, Industry 4.0 adds complexity within and beyond the organization. For implementation, six design principles should be taken into consideration (Hermann et al., 2016).

- Interoperability: the ability of CPS to exchange with each other and make use of information through standardization.

- Virtualization: creating a virtual copy of the physical world.

- Decentralization: working autonomously thanks to embedded computers and technologies allowing for more agility.

- Real time capability: the ability to collect and analyse data in real time by using IoT and its supporting technologies (RFID tags, sensors, actuators...).

- Service orientation: enabling the services of companies, CPS, and humans to be made available to use by other participants (other CPS, companies...).

- Modularity: ability to adapt rapidly to changes in demand such as seasonal fluctuations or changes in products' characteristics by replacing or expanding individual modules.

While each Industry 4.0 design principle delivers value in its own right, that value is amplified when multiple design principles work together to support new, more efficient and more flexible processes. A hands-on example is a production line where a product interacts with different machines, intelligence must be decentralized across the various machines used in the process and all process components must be interoperable and able to respond in real-time to requests from 
the product. In addition, the process must be modular to support customization and may be monitored through virtualization. Finally, service orientation enables the approach by which products can access the services of machines.

\subsection{Engineering management}

Engineering management (EM) in general is the process of designing and maintaining an environment for technological problem solving of engineering and organizational, administrative and planning abilities of management (Kopacek, 2019). Successful EM requires experience in both engineering and business, with a focus on three areas:

- Information Technologies (IT), such as software design, data mining, etc. as well as organizational issues related to the use of these technologies, to support effective decision making.

- Supply chain management for planning the good, services and related information.

- Operations research to support decision making.

Four functions characterize the work of an engineering manager: planning, organizing, leading and controlling (Essila, 2018). Planning is a process of setting objectives and making decisions to achieve them. The decision making process relies heavily on the way the problem is structured and is affected by the conditions regarding the outcome of each alternative (certain, risky or uncertain) and the decision maker's own style (Essila, 2018). The second major function is organizing, which refers to the process of assigning tasks to employees, allocating resources and arranging coordinated activities to implement plans. This function requires qualities such as selfawareness, self-regulation, motivation, empathy and social skills. The last function of an engineering manager is controlling, which means evaluating performances and taking actions to meet the targets. Indeed, throughout the process, conditions can change and the objectives should be adapted to reflect new conditions or there might be some deviations that must be addressed to get back on track.

\subsection{Project management}

Project management and engineering management are often confused. However, they differ in terms of environment and scope, meaning they vary by who and what they manage, and the length of the position (Keys, 2021). Project management is concerned with increasing project success and sustaining their benefits. In this sense, project management can be seen as one of the key areas of engineering management.

Project management is the application of knowledge, skills, tools and techniques to project activities and tasks to meet the project requirements. The main functions of a project manager are initiating, planning, executing, monitoring and controlling, and closing (Heagney, 2012). The role of a project manager (PM) is that of an enabler (who helps the team get the job done and provides them with the needed resources), and also of a leader who ensures that everyone in the team 
shared the same goal to be achieved at the end of the project, and to identify all the work to be done by constructing a good work breakdown structure (WBS).

The PM should be an integrator and coordinate every activity with the team in order to achieve the desired project outcomes. He/she also needs to be a scope manager defining the project boundaries, subdividing the work into manageable components with deliverables, verifying that the amount of work planned has been achieved, and specifying scope change control procedures. Time management skills are also required to define a schedule for the project and ensure the work is done according to that schedule, as well as cost management skills which involves estimating the cost of resources and tracking it to respect the budget. A PM must also possess some qualitybased knowledge to ensure quality and ability to deal with risks systematically, to be a good human resource allocator and a good communicator to share information with all project stakeholders during the whole life cycle. He/she should not handle technical issues. Instead, he must ensure that the Performance requirements, Cost, Time and Scope targets are met. A PM is proactive i.e. he/she observes what needs to be done and does it, under the condition of a complete understanding of the vision set by the organization (PMI, 2017).

\section{$3 \quad$ Industry 4.0 and engineering and project management}

Project and engineering management in the Era of Industry 4.0 is becoming more and more challenging, because of the mentioned transformations and emerging technologies (Win and Kham, 2018). In fact, it is no longer a question of managing people or machines separately, because new connections will be created within and beyond the organization, forming a sociotechnical system of humans and machines. This requires a different level of management based on a huge amount of data that will need to be collected and analyzed (Hirman et al., 2019). Furthermore, in Industry 4.0 all stakeholders are involved in decision making (Ibrahim et al., 2017). Moreover, production will be configured dynamically based on the current demand, which means that the original design may change at any time. As a result, the integrated management of the projects will become increasingly important in order to ensure agility and efficiency towards organization's goals. Therefore, project managers and teams will require additional soft and hard skills than those needed in the past and a greater degree of autonomy. Project teams will be increasingly distributed in different places of the world and have their own cultural and professional identity that needs to be integrated.

A literature review by Ibrahim et al. (2017) delivers a nonexclusive list of characteristics, which include soft skills and hard skills. Because of the new interactions with stakeholders, project and engineering managers require new soft skills, such as communication skills (information sharing in real time with stakeholders), team management (e.g. empower team), and management of unforeseen events. In addition to the traditional hard skills, Industry 4.0 projects require a full comprehension of the Cyber-Physical concept from the project and engineering managers along with deep domain knowledge. The most important hard skill for project and engineering managers 
is experience with innovative technologies and projects, predictive algorithms and big data analysis that will help them manage projects correctly and stay focused on the objectives to be achieved.

An output oriented model was proposed, which considers that competencies are related to certain tasks. The model classifies competencies into Personal, Social and Domain related (Erol et al., 2016). Furthermore, several articles insist on the necessity to adopt new ways of learning to succeed this transformation and enable future engineers to acquire the knowledge and skills needed. One of the teaching demonstration formats that was repeatedly mentioned is learning factories for the results they have shown in disseminating Industry 4.0 technologies and the development of new competencies (Leal et al., 2020).

\section{$4 \quad$ Interviews and results discussion}

\subsection{Questionnaire design}

A questionnaire on Industry 4.0 and engineering and project management was designed based on findings from the literature. The questionnaire was prepared in order to ask respondents (experts and researchers) about the most required skills and competencies required for an engineer specialized in project and engineering management to successfully pilot projects within industry 4.0. The information from the questionnaire is collected and analysed in order to design a comprehensive framework to serve as a support or guide for future engineers and professionals desiring to adopt industry 4.0 paradigm. The questionnaire is composed of the following sections: respondent profile; design principles knowledge to assess the degree of attention needed for technical competencies and soft skills required within curriculum dedicated to industry 4.0; teaching and learning formats that are best suited to developed engineers and projects managements' competencies, knowledge and skills.

To ensure that the questionnaire is suitable and covers the most complete spectrum possible, we pre-tested it with five Industry 4.0 experts acting as respondents. More precisely, these experts have different functions and positions increasing the diversity of their points of view: two researchers actively leading and participating to I4.0 initiatives, two consultants with experience in I4.0 and one manager, all of the experts have background in areas closely related to project and engineering management.

\subsection{Technical competencies requirements}

The first set of questions aims to identify, among nine categories of technologies, those which are considered to be the most relevant and the level of mastery to be acquired by project and engineering managers. Our respondents are particularly unanimous in indicating that data communication, networks and system automation (embedded systems, Internet of Thing, Cloud Systems...) are crucial technologies and that a particular importance should be given to them. 
Then follow technologies related to novel human-machine interfaces (technology-assisted work systems, VR/AR technologies, human-robot collaboration...), as well as data science and advanced (big data) analytics. Nevertheless, according to the respondents, automatic robots as well as "real time" are not necessarily to be prioritized insofar as these are specific technologies which will probably not concern all organizations.

In terms of level of mastery, the ranking of priorities is changing. Indeed, project and engineering managers are expected to have an experience level of mastery when it comes to technologies relating to closed-loop integrated products even though the degree of importance to be given to them was relatively moderate. The classification made by our Industry 4.0 experts, however, shows the same two technologies (namely autonomous robots and real-time inventory and logistics optimization systems) as being those requiring a lower level of mastery compared to the other ones.

Figure 1 highlights the measurement scales evaluated by the respondents allowing a better visualization of the levels of importance and mastery to be granted to the various technologies of Industry 4.0.

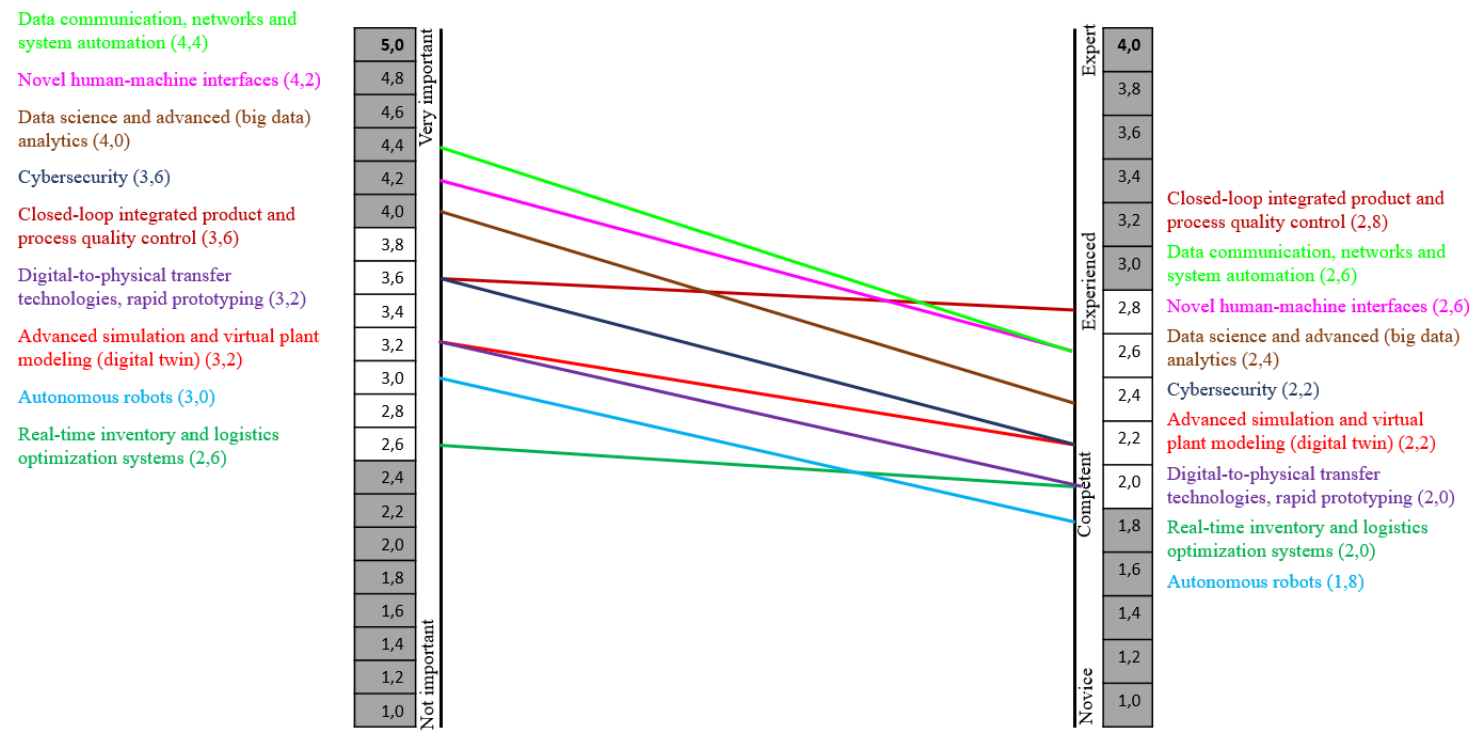

Fig. 1. Level of importance of the Industry 4.0 technologies and their required degree of mastery

The fact that the experts did not assign an "expert" level of proficiency to the various areas of Industry 4.0 is consistent with the answers they provided to the following question. It relates to the differences they established between project and engineering managers on the one hand, and experts on the other. According to the respondents, a project and engineering manager brings a generalist approach, scientific and technical knowledge, which should allow understanding and dialogue with experts. They have the ability to understand the different functions of the 
organization through a transversal approach to be able to pilot, supervise and coordinate various projects and missions. Consequently, they will have to integrate and implement the solutions defined by the expert. In addition, thanks to their transversal knowledge, engineers are equipped to identify the right people to turn to, in particular experts who can solve problems. Another distinction raised relates to the level of autonomy to be achieved for project and engineering managers, which should enable them to understand the need (in particular of the customer or of a function of the organization) and be able to transcribe this need to the expert who will then be responsible for finding the appropriate solution.

\subsection{Soft skills and learning modes requirements}

The next set of questions relate to industry 4.0 competencies in terms of personal/soft skills. As mentioned previously, the literature provides a wide variety of them, that we have consequently sequenced within our questionnaire by clustering them into the following categories. Individual skills that are based on a critical attitude, one's flexibility at work, and the ability to transform one's way of managing; the social skills of mediator on the one hand, and one's ability to mobilize social media to facilitate cooperation among a team or a network; and finally larger categories of soft skills such as leadership, communication, problem solving, or even entrepreneurial skills.

Our results show that that the skills expected of an engineer or project manager in the context of Industry 4.0 are based on their ability to solve problems and to play the role of integrator. Although problem solving is the expert's prerogative (according to the distinction made previously), the ability of the project and engineering manager to identify the right interlocutor who will know how to design an adapted solution is fundamental. Given the uncertainty that organizations can find themselves in when faced with major technological changes in their production system, this problem-solving skill (regardless of its nature) must be nurtured throughout project and engineering manager's education.

As mentioned earlier, project and engineering managers are a key to create links within a network, serving as integrators or mediators. To address this ability, their communication skills are considered by the respondents to be of the utmost importance. Indeed, thanks to their training, these individuals acquire strong notions in various areas that they must be able to relate to each other. In addition, it helps them connect domains that would otherwise have difficulties understanding each other. This interdisciplinary characteristic is fundamental in developing a solid network on which the company can rely to further expand its evolution towards Industry 4.0 .

The final part of our questionnaire aimed to identify ways of teaching students and practitioners to prepare them for the reality and complexity of the field. Providing access to learning factories seems to be the most effective way according to the respondents. Following this teaching format, we find the use of flexible physical production systems laboratory, and then the cooperation with 
industrials within concrete projects to be developed. By highlighting these three formats as the most relevant, our experts highlight the underlying idea that students and practitioners learn best by doing (Maytorena et al., 2007; Savelsbergh et al., 2016). It is therefore necessary to move from traditional curriculum towards more frequent problem oriented experimental learning through industry/university or student/industry collaborations.

\section{Conclusion and perspectives}

This paper has sought to investigate the implications of industry 4.0 for project and engineering management learning requirements. The results reported in this paper are based on the literature and on interviews carried out with five experts. The main objective of these interviews was to test our questions and identify gaps or misunderstandings in the way we formulated them. The administration of this questionnaire on a much larger sample and scale (at the international level) should make it possible to consolidate the opinions of the respondents (or to refute them). In the meantime, it will allow us to present a roadmap for academics in order to help them offer trainings in line with the expectations of the industry 4.0.

\section{Acknowledgements}

This work is partly supported by Auvergne Rhône Alpes (AURA) Region through VARIETY project. The authors would also like to thank K. Slimani for her support.

\section{References}

Keys, J.: Difference Between Engineering Management \& Project Management, https://study.com/academy/popular/difference-between-engineering-management-projectmanagement.html, last accessed 2021/01/30 (2021).

Project Management Institute - PMI: PMBOK® Guide - Sixth Edition, PMI, Pennsylvania (2017).

Erol, S., Jäger, A., Hold, P., Ott, K., Sihn, W.: Tangible Industry 4.0: A Scenario-Based Approach to Learning for the Future of Production. Procedia CIRP, 54, pp. 13-18 (2016).

Heagney, J.: Fundamentals of Project Management - Fourth Edition, American Management Association, AMACOM (2012).

Hermann, M., Pentek, T., Otto, B.: Design Principles for Industry 4.0 Scenarios. In: Proceedings of the $49^{\text {th }}$ Hawaii International Conference on System Sciences, pp. 3829 - 3837 (2016).

Hirman, M., Benesova, A., Steiner, F., Tupa, J.: Project management during the industry 4.0 implementation with risk factor analysis. Procedia Manufacturing, 38, pp. 1181 - 1188 (2019).

Ibrahim, R., Boerhannoeddin, A., Bakare, K.: The effect of soft skills and training methodology on employee performance, European Journal of Training and Development, 41(4), pp. 487-49 (2017).

Kopacek, P.: Higher education in engineering management with impacts of TECIS. IFACPapersOnLine, 52(25), 164-167 (2019).

Leal, L. F., Fleury, A., \& Zancul, E.: Starting up a learning factory focused on industry 4.0. Procedia Manufacturing, 45, pp. 436-441 (2020). 
Calisir, F., Akdag, C. (Eds.): Industrial Engineering in the Industry 4.0 Era, Lecture Notes in Management and Industrial Engineering, Springer, Austria (2017).

Win, T.Z., Kham, S. M.: Transformation of Project Management in Industry 4.0, 12 $2^{\text {th }}$ International Conference on Project Management, pp. 37-44 (2018).

Essila, J.C.: Engineering Management: The Evolution, Conceptual Model, and Social Responsibility of an Emerging Discipline, International Journal of Operations Research and Information Systems (IJORIS), 9(4), pp. 36-50 (2018).

Maytorena, E., Winch, G. M., Freeman, J. Kiely, T.: The Influence of Experience and Information Search Styles on Project Risk Identification Performancell, IEEE Transactions on Engineering Management, 54(2), pp. 315-326 (2007).

Savelsbergh, C., Havermans, L., Storm, P.: Development paths of project managers: What and how do project managers learn from their experiences? International Journal of Project Management, 34(4), pp. 559-569 (2016). 